DOI: 10.17707/AgricultForest.61.4.35

\begin{abstract}
Rossella de VITO*, Ivan PORTOGHESE, Alessandro PAGANO, Umberto FRATINO ${ }^{1}$
\end{abstract}

\title{
INTEGRATING WFA AND HYDROLOGICAL MODELLING FOR ASSESSING SUSTAINABILITY OF THE AGRICULTURE IN A COMPLEX ENVIRONMENTAL SYSTEM
}

\begin{abstract}
SUMMARY
Water Footprint Assessment (WFA) is an innovative tool able to estimate consumptive use of water resources in various fields. WFA has been applied in several contexts, although most relevant applications concern the analysis of water exploitation in agriculture. Currently, most of research activities aim to use WFA to support the definition of sustainability criteria in water management issues.

In this work, WFA methodology was implemented mainly to analyse the impact of agricultural activities on the available water resources in an area located in Apulia region (Southern Italy). The study area is relevant for its hydrogeological complexity: it comprises two interconnected coastal lakes, one with freshwater and one with brackish water, the former being the major water source for both irrigation and drinking purposes. Moreover, the area is a renowned tourist destination, thus deserving a significant environmental value, which contrasts with the current overexploitation due to the irrigation requirements and to the touristic water demand.

Crop water requirements (mainly grapevine and summer vegetables) were computed using CROPWAT software and the obtained results used for estimating a water footprint indicator.

The WFA methodology was also coupled with a hydrological model able to describe the main dynamic aspects of the system (e.g. water withdrawals, interactions between surface water and groundwater, etc.). The hydrological model was built based on a large dataset deriving from continuous monitoring activities performed during a whole irrigation season.

The integration of information, data and models was the basis to support the definition of sustainability criteria in a complex system, characterized by competing water uses and emerging issues related to the environmental conservation
\end{abstract}

Key words: water footprint assessment, environmental sustainability, hydrological modelling.

\footnotetext{
${ }^{1}$ Rossella de Vito*, (corresponding author: rossella.devito@poliba.it), Umberto Fratino, Technical university of Bari, Department of Civil, Environmental, Building Engineering and Chemistry ITALY, Ivan Portoghese, Alessandro Pagano, Water Research Institute, National Research Council of Italy, ITALY

Paper presented at the $6^{\text {th }}$ International Scientific Agricultural Symposium "AGROSYM 2015"

Note: The authors declare that they have no conflicts of interest. Authorship Form signed online.
} 


\section{INTRODUCTION}

One of the main challenges in water resources management is reaching sustainability, especially when multiple concurrent water uses should be complied within specific environmental constraints.

Population growth and climate change can determine significant impacts on the agricultural sector. The increase in water consumption to meet future irrigation demands faces one of the main environmental issues (Chapagain et al., 2009).

Scientists have focused on the concept of virtual water (Allan, 1993) and water footprint (Hoekstra, 2003). Recently, Hoekstra and Chapagain (2008) have shown as the choice to introduce water use consumption on the label products contributes to raise consumer awareness to the problem of water consumption.

In this context, the aim of this work is to define a methodology to assess the impact of agricultural activities on water resources in an area characterized by concurrent water uses and at the same time, to identifying sustainability criteria in a system characterized by an high environmental value.

An integrated approach between a hydrological model describing the dynamics of water systems within the study area, and Water Footprint Assessment (WFA) model was developed.

\section{MATERIAL AND METHODS}

\section{Study Area}

The research activity is focused to the analysis of a complex hydraulic system constituted by two interconnected coastal lakes, located in Apulia region (Southern Italy) within Otranto municipality. The first, named 'Alimini Piccolo' is a fresh water lake, connected through a connection channel ('Lu Strittu') with a brackish water lake called 'Alimini Grande' (figure 1). The latter flows directly to the sea. The presence of a sill in the connection channel and the interactions with groundwater significantly affect the behaviour of the hydraulic system during the year.

The study mainly focuses on 'Alimini Piccolo' which is the key water source for irrigation and drinking purposes in the area and represents a renowned touristic destination too. Several concurrent water uses have to be guaranteed, preserving the environmental value of the area. Alimini Piccolo has an area of approximately $1.2 \mathrm{~km}^{2}$, an average depth of approximately $1.5 \mathrm{~m}$, and may provide an average total water volume of approximately $1.2 \mathrm{~mm}^{3}$.

Irrigation and drinking withdrawals take place in three distinct locations as shown in figure 1 . The first one, 'Casa Monsignore', is a water source located nearby Lu Strittu channel, and is mainly used for drinking uses. Two other withdrawals are instead for irrigation and are located in two different plants ('East Fontanelle' and 'South Fontanelle'). The irrigation system is based on two identical simple schemes, both equipped with a pumping station, a pressurized conveyance pipe, and a distribution network that conveys water to single farms through rotational turns. The overall area of the consortium is about 974 ha and 
the most widely diffused crops, according to a census performed in 2010, are olives, grapevine $(\approx 53 \mathrm{ha})$ and vegetables (particularly tomatoes $\approx 144 \mathrm{ha}$ ).

It should be also considered that although a significant part of irrigation requirements can be fulfilled by Alimini Piccolo, a significant amount of groundwater is usually through wells.

Modelling the interaction between the surface water system and groundwater is particularly challenging, but crucial in order to assess the sustainability of the agricultural activities in the area.

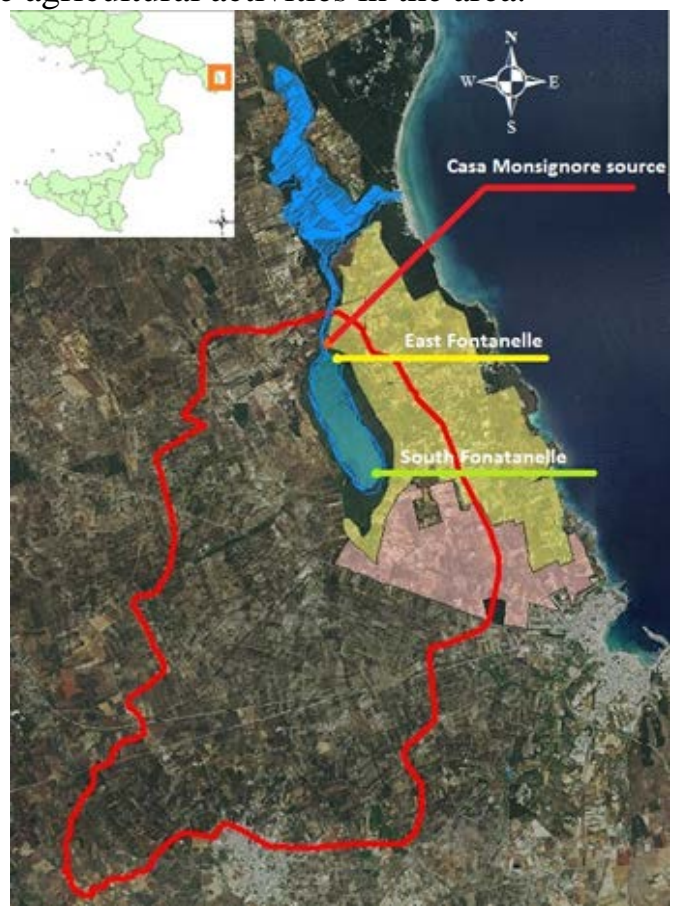

Figure 1. Study area: the red line is hydrological basin of Alimini Piccolo lake; the pink and yellow areas are the two irrigation district respectively

South and East Fontanelle

\section{Hydrological Model}

The hydrological model consist of three sub-models: the first one is used to estimate the soil water balance with semi-distributed parameters, the second for computing the groundwater recharge with lumped parameters, and the last one to evaluate the water balance of the lake. The surrounding watershed was divided in two sub-units, both of them contributed to the lake's inflow with a slow and a fast component.

The Figure 2 shows a general scheme of the proposed model, that is able to estimate the various components of the water balance with daily resolution.

Going further into details, the input data (precipitation $P$, evapotranspiration $E$ and irrigation withdrawals from the lake and from 
groundwater $(I)$ ) are used by the model to calculate the water content in the soil $\left(S_{w t}\right)$ in order to compare it with the maximum water capacity of the soil $\left(S_{w c}\right)$.

When $S_{w t}$ is higher than the $S_{w c}$, the water surplus $\left(S_{w t} S_{w c}\right)$ gives a daily volume of water $(Y)$ from which both runoff and deep percolation originate. The runoff determines a fast flow component to the lake $\left(Q_{\text {fast }}\right)$, whereas the deep percolation, instead, slowly reaches the groundwater and after the lake $\left(Q_{\text {slow }}\right)$. It implies that an inflow $\left(Q_{i n}=Q_{\text {fast }}+Q_{\text {slow }}\right)$ reaches Alimini Piccolo lake and consequently a discharge $\left(Q_{\text {out }}\right)$ outflows from it and reaches Alimini Grande lake. The model takes into account more water losses as evaporation $(E)$ from the lake and the withdrawals for both irrigation and drinking purposes.

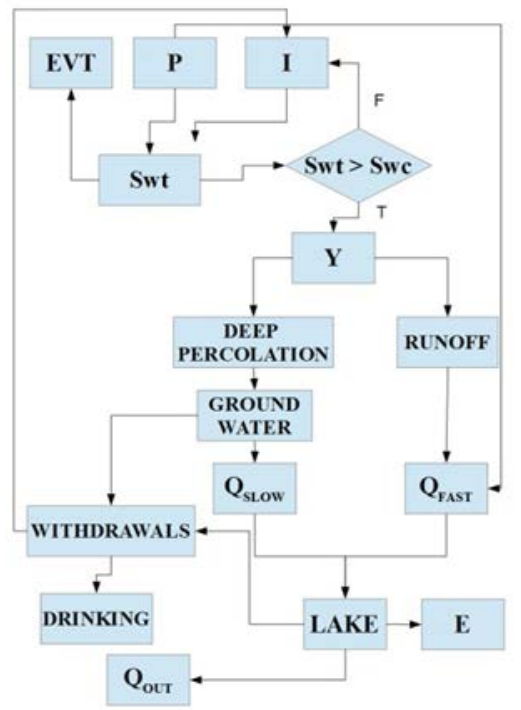

Figure 2. Hydrological model

The proposed model is able to simulate the trend of the water volume stored in the aquifer and the inflow to the lake and to reproduce the water levels in the lake. The model was validated by means of data coming from qualitative and quantitative monitoring activities, performed during the year 2014. Particularly, four multi-parameters sensors were located in four different points for a real time measurement of salinity, temperature and water level. In addition, a monitoring campaigns were made for recording the water level of the groundwater, and for assessing the water quality. The water withdrawals were monitored through a PLC system installed on the pumping stations

Simulations were made related to the time interval 2007 - 2014, based on available data on volumes required for irrigation use, assuming constant the drinking water demand.

The irrigation withdrawals from the lake $\left(W_{L}\right)$ ware estimated, referring to the water volumes resulting by consortium bills $\left(V_{d}\right)$, as follows: 


$$
W_{L}=\frac{V_{d}}{E_{c}}(1)
$$

where $E_{c}$ is the conveyance efficiency. The conveyance efficiency was estimated as the ratio between the $V_{d}$ and the monitored value $V_{\text {plc }}$ referred to 2014 (Hsiao et al, 2007). The calculated value, equal to 0.68, was assumed constant in all analysed period.

The irrigation withdrawals from groundwater $\left(W_{G W}\right)$ were computed starting from CROPWAT's results, as difference between the gross irrigation (GI) in optimal irrigation conditions and the volume of water delivered to the farm $\left(V_{d}\right)$, as follows:

$$
W_{G W}=G I-V_{d}(2)
$$

The drinking water withdrawals were also monitored during 2014 by means of volumetric flowmeters located in "Casa Monsignore" source. Further details on the proposed model are available in de Vito (2014) and Portoghese et al. (2013).

\section{Water Footprint Accounting}

The Water Footprint (WF) is a volumetric measure of water consumption and pollution (Hoekstra et al, 2009) to produce a product, that consists of three components: a) blue WF, which represents the volume of freshwater that it is consumed by the crop and withdrawn from surfaces and ground water; b) the green WF, which is the volume of rainwater stored in the soil as soil moisture and evaporated from it and c) grey WF which is the volume of polluted water that is associated with agricultural production.

In this paper, only the blue and green component of WF were modelled, since they are those directly related to the water availability. Grey WF was instead neglected.

They were computed referring to the green and blue water evapotranspiration provided by CROPWAT software, with irrigation schedule option. This means that the model does not consider the effective precipitation, but includes a daily soil water balance, which keeps track of soil moisture content (Hoekstra et al, 2011).

The irrigation schedule option is based on climate, crop and soil data. The climatic data were taken from a station located nearby the lake. The considered crop were only irrigated ones (grapevine and tomato).

WFA was performed assuming an optimal condition of irrigation The efficiency of the irrigation system is assumed to be approximately $70 \%$,

The blue, $E T_{b}(\mathrm{~mm})$, the green, $E T_{g}(\mathrm{~mm})$ and the total evapotranspiration $E T_{a}(\mathrm{~mm})$ were calculated through equations (3), (4) and (5) More in details, $E T_{a}$ is defined as follows:

$$
E T a=E T b+E T g(3)
$$

$E T b=\min ($ total net irrigation, actual irrigation requirement) (4)

$$
E T g=E t a-E T b
$$


The green water footprint of a crop $\left(\mathrm{m}^{3}\right)$ is calculated as the product between the used volume of green water $\left(C W U_{g}\left[\mathrm{~m}^{3} / \mathrm{ha}\right]\right)$ and the overall cultivated area of the crop, $A$ (ha), as show in equation (6).

$$
\begin{gathered}
\text { WF green }=C W U_{g} * A(6) \\
C W U_{g}=E T g * 10(7)
\end{gathered}
$$

On the other hand, the blue $W F\left(\mathrm{~m}^{3}\right)$ is calculated as the product between the used volume of blue water $\left(C W U_{b}\left[\mathrm{~m}^{3} / \mathrm{ha}\right]\right)$ to the overall cultivated area of the crop, $(A[h a])$, as show in equation (8):

$$
\begin{aligned}
\text { WFblue } & =\text { CWUb } * A(8) \\
C W U b & =E T b * 10
\end{aligned}
$$

\section{RESULTS AND DISCUSSION}

The model has been calibrated using data coming from the monitoring campaign performed in 2014. Once calibrated, the model was used to simulate the period between 2007 and 2014, when climate data were available. The results of model calibration, performed with respect to the water depths and available water volumes in the lake, are proposed in Fig. 3.

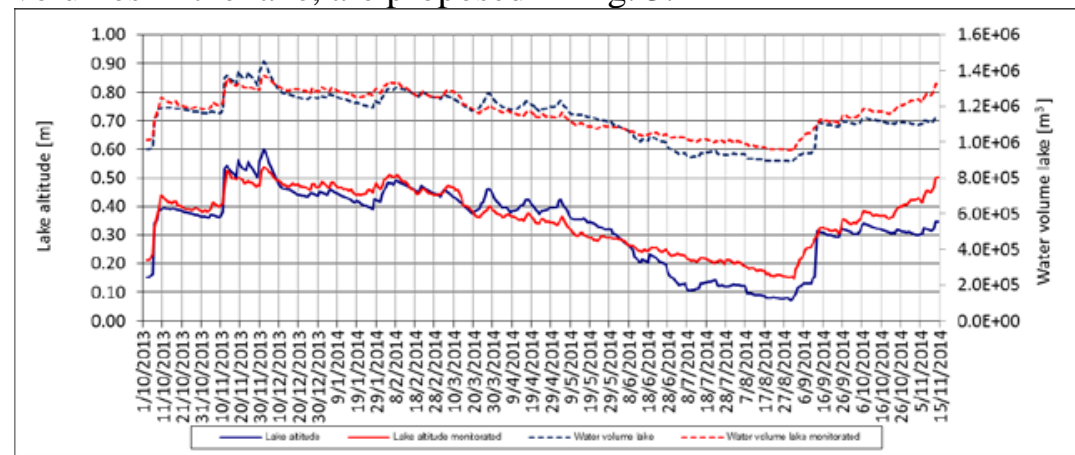

Figure 3. Model calibration

In fig. 4, the WF blue associated to the irrigated crops (tomato and grapevine) is represented. The figure clearly shows that approximately $1 \mathrm{~mm}^{3}$ of water is needed on average during each irrigation season for satisfying the water requirement for agriculture in the area.

Figure 5.a.b proposes a simple overview of the obtained results for the whole analysis period. The graph in figure 5.acompared the altitude of the lake and the volume of blue and green WF. Being the average sea level, the chosen sustainability criterion, from the graph results that the hydraulic balance is always ensured. The figure clearly evidences that the water demand for agriculture has significant impact. In fact, in 2007, 2008 and 2012, the lake level drops below the acceptable sustainability threshold. 
The graph in Figure 5.b shows the relation between withdrawals from the lake and groundwater and the blue WF component.

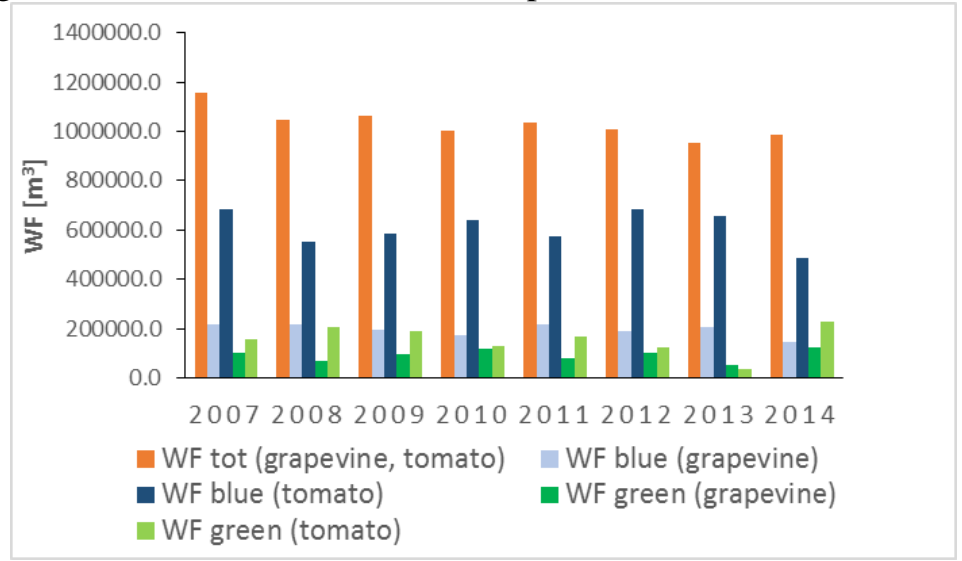

Figure 4. Water Footprint accounting results

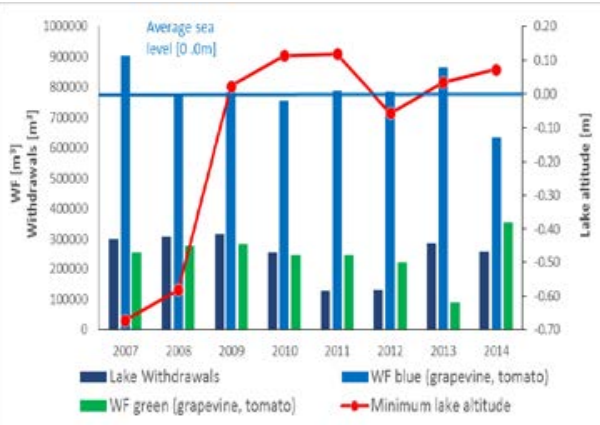

a)

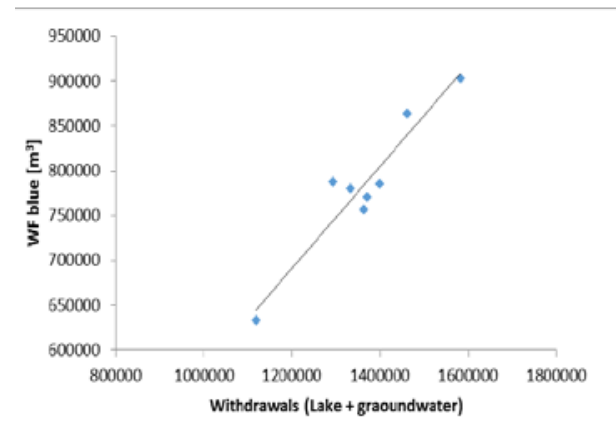

b)

Figure 5. Integrated approach results

\section{CONCLUSIONS}

The present work focuses on the definition of a methodology for the assessment of water uses in a complex hydrological system, constituted by two interconnected coastal lakes. Agricultural activities and water demand may significantly impact water resources and the local environmental conditions.

An integrated approach between hydrological model and water footprint assessment was then proposed in the paper. By a first analysis of the obtained results, the proposed methodology seems be a valuable tool for defining the impacts of concurrent activities on water resources in a complex system. The results of such modelling may be highly helpful to identify and select responses and policies for meeting specific sustainability criteria.

Future research activities will be mainly oriented to an improvement of the proposed methodology, and to the implementation of specific modelling scenarios. 


\section{REFERENCES}

Allan, T., (1993). Fortunately there are substitutes for water: otherwise our hydropolitical futures would be impossible, Conference on Priorities for Water Resources Allocation and Management, London;

Chapagain, a. K. and Orr, S. (2009). An improved water footprint methodology linking global consumption to local water resources: A case of Spanish tomatoes. Journal of Environmental Management, 90(2), 1219-1228;

de Vito R., (2014).Modellazione di bilancio idrologico di un Sistema lacustre in zona costiera: Il caso del lago Alimini Piccolo (Hydrological modelling of a lake system in the coastal area: The case of Alimini Piccolo lake), thesis degree, Technical Univeristy of Bari (in Italian);

Hoekstra, A.Y. and Chapagain, A.K. (2008). Globalization of Water: Sharing the Planet's Freshwater Resources,Blackwell Publishing, Oxford;

Hoekstra, a. Y., (2003). Virtual Water Trade. International Expert Meeting on Virtual Water Trade, 12(12), 1-244.

Hoekstra, A. Y., Chapagain, A. K., Aldaya, M. M., Mekonnen, M. M. (2009). Water Footprint Manual State of the Art 2009;

Hoekstra, A. Y., Chapagain, A. K., Aldaya, M. M., Mekonnen, M. M. (2011). The Water Footprint Assessment Manual;

Hsiao, T. C., Steduto, P., Fereres, E. (2007). A systematic and quantitative approach to improve water use efficiency in agriculture. Irrigation Science, 25(3), 209-231;

Portoghese, I., de Vito, R., Fratino, U., Pagano, A., Vurro, M., Caputo, M.C., De Carlo, L., and Masciale, R. Un modello afflussi-deflussi per lo studio del bilancio idrogeologico del Lago Alimini Piccolo nella penisola Salentina (An inflowoutflow model to the study of the water budget of Alimini Piccolo lake in the Salento Peninsula), IDRA 2014, Bari (in Italian). 